\title{
Optical Properties of DY Doped Strontium Aluminate Nanophosphors
}

\author{
V. T. Jisha ${ }^{1}$, Sajikumar .A .C ${ }^{2}$ \\ ${ }^{1}$ Research Centre, S.T. Hindu College, Nagercoil -629 002, Tamilnadu, India \\ ${ }^{2}$ Malankara Catholic College, Kaliyakavilai, Kk. District
}

\begin{abstract}
Dy doped SrAlO nano phosphors were synthesized by adopting a simple Sol-Gel Method. X-Ray Diffraction (XRD) profile confirms the monoclinic nature of Mn doped SrAlO nano phosphors. The results show that SrAlO:Dy with an average particle size of 80 nm is formed. In addition, Scanning electron microscopy (SEM) is also used to characterize the synthesized phosphor. The efficiency of the prepared phosphors was analyzed by means of its emission spectral profiles. We also observed a rich IR emission from the prepared phosphors under a Ultra-Violet (UV) source. Such luminescent powders are expected to be applied as IR sensor and MRI device applications
\end{abstract}

Keywords: Phosphors, optical properties, luminescence, XRD, SEM, Dysprosium

\section{Introduction}

The importance of rare earth ions as efficient emitter in avariety of solid-state matrices is well known. Among rare earth ions, Eu/Dy is often employed by researchers for making red emitting phosphors, where the prominent 612 $\mathrm{nm}$ emission band arises from electric dipole moment allowed transitions [1]. The long lasting phosphors (LLP) oxide materials have been developed to replace the conventional sulfide afterglow materials because of their improved luminescent properties such as high initial brightness, long lasting time, suitable emission color and satisfactory chemical stability [2-4], which result in an unexpectedly large field of applications e.g. luminous paints in highways, airports, buildings and ceramic products [5]. With the development of newer technologies, several kinds of chemical synthesis techniques such as co-precipitation [6], sol-gel [7], reverse micro emulsion [8] and combustion methods [9-10] have been employed to prepare $\mathrm{SrAl} 2 \mathrm{O} 4$ and its phosphors [11]. Comparing these methods, sol-gel synthesis possesses some benefits, namely, relatively low preparation temperature, easy control of the stoichiometry, high levels of product homogeneity, and no need for the use of expensive equipment. In this article, we reported the synthesis of nanostructured $\mathrm{SrAl}_{4} \mathrm{O}_{7}$ doped with Dy via Sol Gel synthesis and effects on PL properties were investigated.

\section{Experiment}

The materials used for synthesis are strontium nitrate a aluminium nitrate and all other materials are $99.9 \%$ pure. The procedure of synthesizing nanoparticles is thoroughly described as follows: 98 wt.\% of $2 \mathrm{M}$ Strontium acetate $\left[\left(\mathrm{CH}_{3} \cdot \mathrm{COO}\right)_{2}\right.$ Sr. $2 \mathrm{H}_{2} \mathrm{O}$ was dissolved in $25 \mathrm{ml}$ of 2 methoxyethanol with vigorous stirring. 1 wt. $\%$ of $2 \mathrm{M}$
Dysprosium nitrate $\left[\left(\mathrm{CH}_{3} \cdot \mathrm{COO}\right)_{2}\right.$ Dy. $\left.2 \mathrm{H}_{2} \mathrm{O}\right]$ was dissolved in $25 \mathrm{ml}$ of 2-methoxyethanol with vigorous stirring. Simultaneously, 1 wt.\% of $2 \mathrm{M}$ Aluminum acetate $\left[\mathrm{C}_{4} \mathrm{H}_{6} \mathrm{AlO}_{4} \cdot 4 \mathrm{H}_{2} \mathrm{O}\right]$ was dissolved in $25 \mathrm{ml}$ of 2methoxyethanol with vigorous stirring and subsequently, it was added to the to the first solution to reach $50 \mathrm{ml}$ in total. Then it was stirred for $30 \mathrm{~min}$ at room temperature for the second time. Ammonia was slowly added to this solution with a constant stirring until a $\mathrm{pH}$ of 10.5 was achieved. After the stirring of the solution for $30 \mathrm{~min}$, acetic acid and ethylene glycol in the ratiol:1 was added to the solution. The sol was heated at $80^{\circ} \mathrm{C}$ while being mechanically stirred with a magnetic stirrer. As the evaporation proceeded, the sol turned into a viscous gel. The gel was aged for $2 \mathrm{~h}$ and then dried at $100^{\circ} \mathrm{C}$ for about $5 \mathrm{~h}$. The resulting materials were well grinded and annealed at $950^{\circ} \mathrm{C}$ for $5 \mathrm{~h}$ to obtain Dy doped $\mathrm{SrAl}_{4} \mathrm{O}_{7}$ nanopowders. For the preparation of the gel precursors with different $\mathrm{wt} \%$, the same procedure was repeated with the $\mathrm{wt} \%$ of Dysprosium nitrate being varied to $0.5,2,3,4$ and 5 .

\section{Characterization}

\section{SEM Analysis}

The SEM study is carried out to investigate the surface morphology and the average crystallite size of the synthesized phosphors. Fig. 1 shows the representative SEM micrographs taken for $\mathrm{SrAl} 4 \mathrm{O} 7$ :Dy phosphors at different Dy concentrations. Generally the particles are of irregular shape. SEM was used to study the surface morphology of the films. A representative micrograph of the film is shown in Fig. 2. The micrograph also showed that the particles were interlinked with each other, leading to the formation of big crystals and irregular aggregations formed in the sample. The particle sizes are $80,77,78,75,40,49$ respectively. 


\section{International Journal of Science and Research (IJSR) \\ ISSN (Online): 2319-7064}

Index Copernicus Value (2013): 6.14 | Impact Factor (2015): 6.391
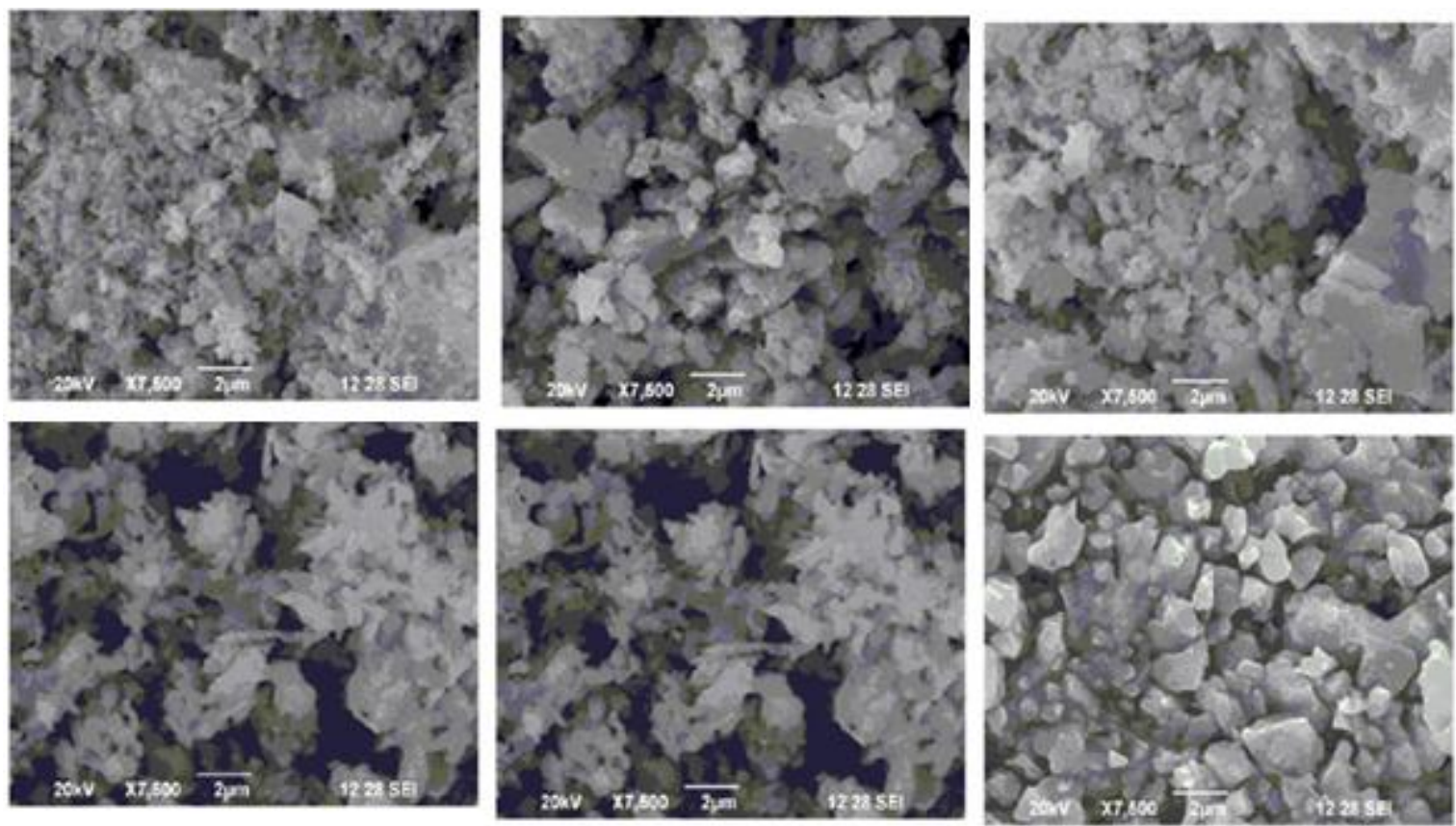

Figure 1: $\mathrm{SEM}$ pictures of $\mathrm{SrAl}_{4} \mathrm{O}_{7}$ :Dy

\section{X-Ray Diffraction (XRD)}

The structure and phase purity of the $\mathrm{SrAl}_{4} \mathrm{O}_{7}$ :Dy phosphor were investigated by XRD. The XRD patterns were obtained and are shown in Fig.2 for SrA1O: Dy. Diffraction patterns were obtained using $\mathrm{CuK} \alpha$ radiation $\left(\lambda=1.54051 \mathrm{~A}^{0}\right)$,at $30 \mathrm{kV}$ and $15 \mathrm{~mA}$. Measurements were made from $2 \theta=10^{\circ}$ to $80^{\circ}$ with steps of $0.02^{\circ}$. The XRD patterns of the powders revealed that the structure of $\mathrm{SrAl}_{4} \mathrm{O}_{7}$ is Monoclinic, which is match with JCPDS data card No. 25-1289. The crystallites are less than approximately $50-90 \mathrm{~nm}$ in size appreciable broadening in the X-ray diffraction lines. SEM images $\mathrm{SrAl}_{4} \mathrm{O}_{7}$ : Dy, which is un-uniform and may be due to the formation of fractal attribution to sort of self organization. SEM image of $\mathrm{SrAl}_{4} \mathrm{O}_{7}$ sintered at $900^{\circ} \mathrm{C}$

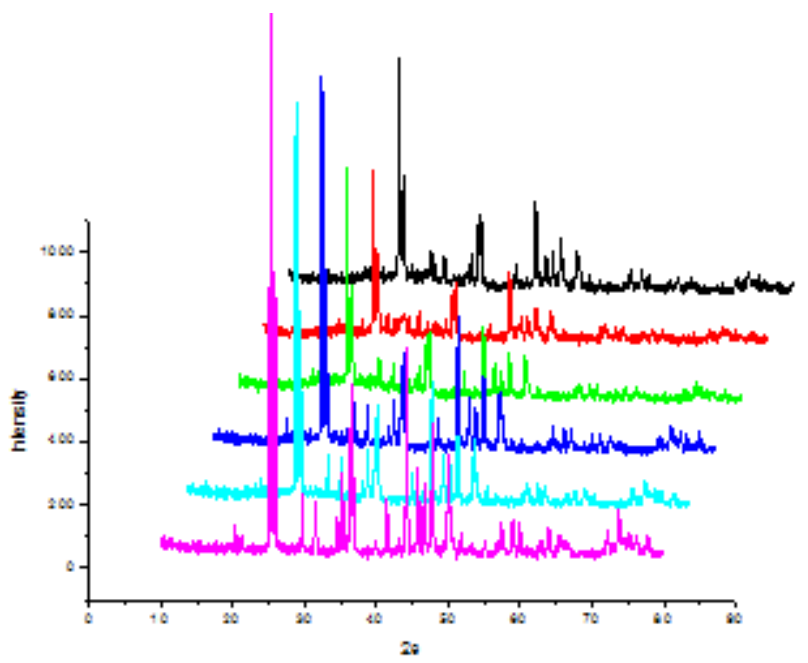

Figure 2:XRD patterns of $\mathrm{SrAl}_{4} \mathrm{O}_{7}$ :Dy

\section{Photoluminesence}

The photoluminescence spectra of $\mathrm{SrAl}_{4} \mathrm{O}_{7}$ : Dy nanoparticles under $360 \mathrm{~nm}$ excitation wavelength is shown in Fig3. The PL emission spectra of all samples exhibit three emission bands with corresponding peak wavelengths of 395 $\mathrm{nm}, 520$ and 790 under excitation of $360 \mathrm{~nm}$. The strong peak showing blue emission at $395 \mathrm{~nm}$ was due to the exciton emission, and weak green emission at $520 \mathrm{~nm}$ was due to oxygen interstitial. The strong UV emission corresponds to the exciton recombination related near-band edge emission of nanoparticles. The green emissions are possibly due to surface defects in the nanoparticles.

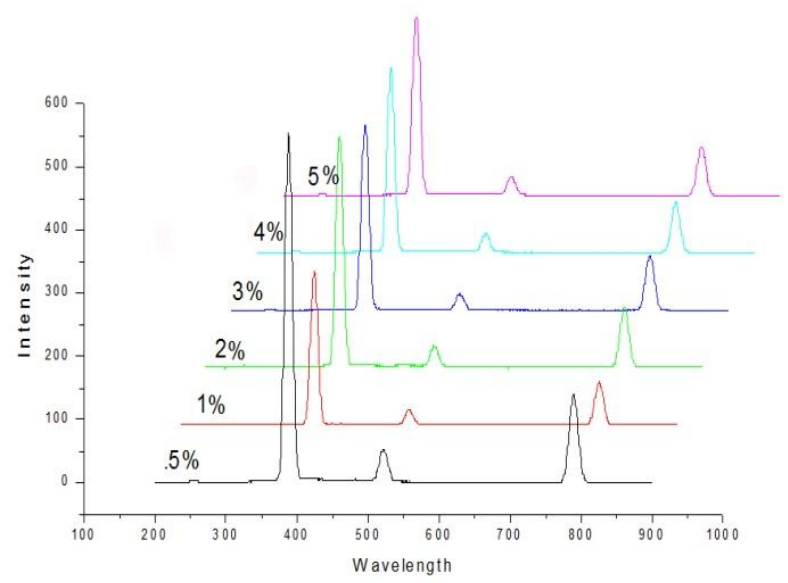

Figure 3: Photoluminescence Spectra of Dy doped $\mathrm{SrAl}_{4} \mathrm{O}_{7}$ at different $w t^{\%} \%$ of Dy

\section{Conclusion}

The phosphors $\mathrm{SrAl}_{4} \mathrm{O}_{7}$ :Dy (at $0.5,1,2,3,4$ and $5 \mathrm{wt} \%$ of Dy) with a monoclinic structure were successfully prepared by Sol-Gel method. The characteristic peaks of SrAl4O7:Dy phosphors were observed and they are located at $395 \mathrm{~nm}$, $520 \mathrm{~nm}$ and $800 \mathrm{~nm}$ which are corresponding exciton emission and the oxygen interstitial.The luminescent intensity of Dy doped $\mathrm{SrAl}_{4} \mathrm{O}_{7}$ nanoparticles increases with increase in the Dy dopant concentration at first and then it decreases. The maximum intensity was achieved for about 1 mol\% Dy $3+$.The photoluminescence investigations reveals that the emission mechanism is governed mainly by defect controlled processes. 


\section{International Journal of Science and Research (IJSR) \\ ISSN (Online): 2319-7064}

Index Copernicus Value (2013): 6.14 | Impact Factor (2015): 6.391

\section{References}

[1] S.K. Sharma, S.S. Pitale, M.M. Malik, M.S. Qureshi, R.N. Dubey, J. Alloy Compd. 482, 468 (2009).

[2] J. Holsa, H. Jungner, M. Lastusaari, J. Niittykoski, J. Alloys Compd. 326, 323 (2001).

[3] A. Nag, T.R.N. Kutty, J. Alloys Compd. 354(1-2), 221 (2003).

[4] Y.H. Lin, Z.T. Zhang, F. Zhang, Z.L. Tang, Q.M. Chen, Mater. Chem. Phys.65(1), 103 (2000).

[5] Y. Murayama, N. Takeuchi, Y. Aoki, T. Matsuzawa, US Patent 5424006, (1995).

[6] M.D. Segall, P.L.D. Lindan, M.J. Probert, C.J. Pickard, P.J. Hasnip, S.J.Clark, M.C. Payne, J. Phys: Cond. Mater. 14, 2717 (2004).

[7] T.Y. Peng, H.J. Liu, H.P. Yang, C.H. Yan, Mater. Chem. Phys. 85, 68 (2004).

[8] C.H. Lu, S.Y. Chen, C.H. Hsu, Mater. Sci. Engg. B 140, 218 (2007).

[9] T.Y. Peng, H.P. Yang, X.L. Pu, B. Hu, Z.C. Jiang, C.H. Yan, Mater. Lett. 58, 352 (2004).

[10]Z.L. Fu, S.H. Zhou, Y.N. Yu, S.Y. Zhang, Chem. Phys. Lett. 395, 285 (2004).

[11]D. S. kshatria, ayush khare, piyush jha, Chalcogenide Letters. Vol. 10, No. 3, March 2013, p. 121 - 129

[12] W. Y. Shen, M. L. Pang, J. Lin, and J. Fang, J. Electrochem. Soc., 152, (2005) H25.

Volume 5 Issue 8, August 2016 www.ijsr.net 